\title{
Crisis Communication at Higher Education Institutions in South Africa: A Public Relations Perspective
}

\author{
${ }^{*}$ S. B. Hussain, V. P. Rawjee \\ Durban University of Technology, South Africa \\ *sameerah@dut.ac.za
}

\begin{abstract}
The higher education sector has undergone dramatic restructuring through incorporations and mergers. This restructuring has led to the breakdown of apartheid racial divides and provided a vision of a single coordinated higher education system. In addition to opportunities various challenges have also emerged from these mergers. One such challenge is that higher education institutions may find themselves in tensions with their partners which may result in disagreements that could lead to crisis situations. In crisis situations, the pace of the conflict accelerates dramatically. This means that the affected parties have to react very quickly or risk having their ability to protect their interests substantially reduced. Implicit in this is the importance of communication. Often in a crisis situation, communication gets distorted; as a result rumors often supplant real facts. Thus, clear communication needs to be pre planned and increased during a crisis. The aim of this research is to investigate the role of communication during the planning and management of a crisis at higher education institutions in KwaZulu-Natal. A qualitative methodology was employed in this study. It reports on the preliminary results of in-depth interviews that were conducted at the four public higher education institutions in KwaZulu-Natal. Themes emanating from the literature review were used to develop an interview schedule which comprised of open-ended and closed-ended questions.
\end{abstract}

Keywords: Crisis, communication, conflict management, higher education institutions

\section{Introduction}

After democracy in 1994, higher education institutions were a key prospect on the change and transformation agenda (May 2004). The Ministry of Education (2001) provided a framework for achieving the vision of a single co-ordinated higher education system in South Africa. In order to meet these goals, various technikons and universities were merged. These mergers brought about both challenges as well as opportunities for higher education. Pityana (2004) explains that some of the opportunities that have resulted from the merger process are that higher education institutions now provide a sphere for public debate and encourage the development of a reflective capacity and a willingness to address and renew ideas and practices. Pityana (2004) further states that one of the challenges have emerged from the merger process, is that institutions find themselves in tensions with their partners. These challenges often lead to crisis situations. It is therefore, imperative that higher education institutions attempt to prepare themselves for these crisis situations. Tench and Yeoman (2006) define a crisis as an event that disrupts normal operations of an organization and if, badly managed, can ruin hard won reputations. When a crisis does occur, events usually unfold rapidly, leaving little time for planning, therefore advance preparation is essential. From this we can note that every organization has to deal with some form crises during their existence, therefore effective planning and management of a crisis is essential for the survival of any organization. Higher education institutions play a critical role in the social, cultural and economic development of any country. According to Higher Education South Africa (HESA) (2008), the purpose of higher education institutions is to meet the learning needs and aspirations of young individuals.

Management at higher education institutions can avoid or be better prepared to handle crises, if they have a crisis communication plan in place and if they communicate effectively during these uncertain periods of time. Apart from having a crisis communications plan, public relations practitioners need to develop communication strategies and processes to influence the cause of conflicts to the benefit of the organizations many stakeholders. This is often referred to as strategic conflict management. Donyale, Padgett, Cheng and Parekh (2013) purport that organizations are required to engage with their internal and external stakeholders about the severity and nature of the crisis. A crisis situation therefore makes it necessary to implement a response strategy as responsibility for the crisis is placed on the organization. Based on this communication is therefore at the heart of a crisis and conflict management and crisis 
communication therefore becomes a public relations issue (Lubbe and Puth, 2000). The outcome of this study is to therefore identify current gaps that exist in current practices of crisis communication at higher education institutions and make suggestions for improving the planning and management of crises communication.

\section{Literature Review}

Strategic Conflict Management: Zhuldz, Onaichan, Surugiu and Mina (2013) purport that an organizations capability to solve conflicting situations is considered to be at the same level and sometimes even more important than planning, communicating, motivating and decision making. Plowman (2005) purports that the public relations practitioner has the ability to fulfill a creative and technical staff role, yet there is a growing demand that it should assume a more strategic management role in an organization. The influence of public relations on the cause of conflict involves reducing the conflict as soon as possible (Wilcox and Cameron 2009). Therefore it can be said that, the public relations practitioner is responsible for determining the stance an organization will take in dealing with the conflict situation and this includes monitoring for threats, assessing them, determining a strategy for the organization and thereafter begin its communication efforts. Wilcox and Cameron (2009) have devised a conflict management lifecycle which is divided into four phases which are the proactive phase, strategic phase, reactive phase and recovery phase.

Figure 1: Conflict Management Lifecycle (Wilcox and Cameron, 2009)

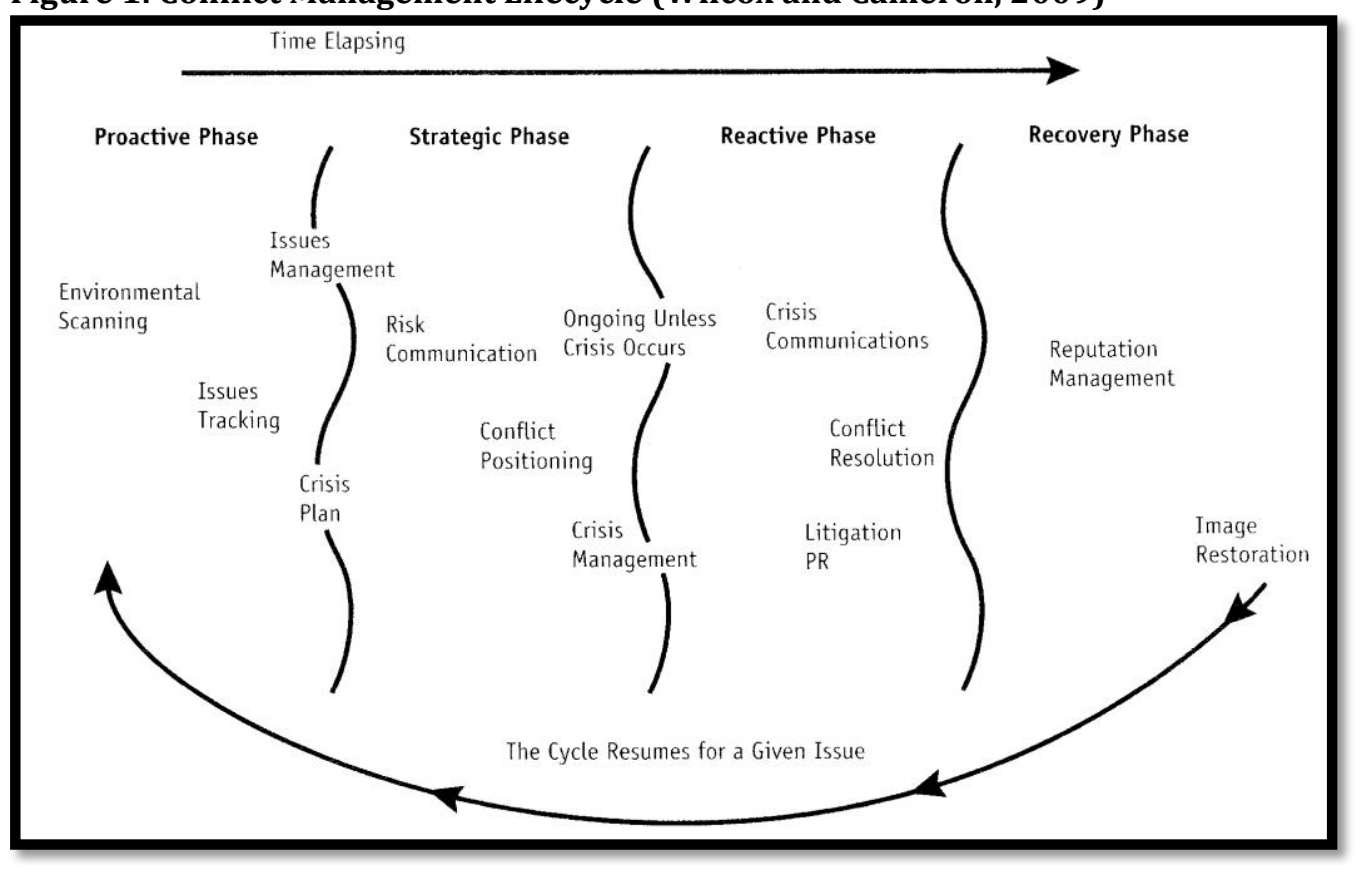

Events move in time from the left to the right through the four phases. At the end of the cycle, persistent issues will require that the process begins all over again from the left side of the cycle to the right. Each of these phases will be discussed below.

Proactive Phase: The proactive phase includes activities and thought processes that can prevent a conflict from arising or from getting out of hand. The first step in this phase can be known as environmental scanning. Barton (2008) defines environmental scanning as the constant reading, listening and watching of current affairs, with an eye to the organizations interests. As issues emerge, issues tracking become more focused and systematic as strategic plans are created to address such issues. In the proactive phase a well run organization will also develop a good crisis plan as its first step in preparing for the worst. This phase encompasses two stages which are issues management and crisis planning.

Issues Management: Skinner and Mersham (2002) explain that the central challenge is for organizations to identify future issues and respond with timely strategies and programs. Therefore issues management can be defined as a proactive early warning process that enables management to be better informed of changes that may take place in an environment that may affect them and it can assists in avoiding 
"surprises" which cost money and time and puts the organizations reputation at risk. They further state that effective issues management requires two-way communication, formal environmental scanning and active sense-making strategies.

Crisis Planning: The Institute for Crisis Management (ICM) (in Center, Jackson, Smith and Stansberry 2008) defines a crisis as a signified business disruption that stimulates extensive news media coverage. The resulting public scrutiny will affect the organizations normal operations and could also have a political, legal, financial and governmental impact on the organization. Schultz, Utz and Goritz (2011) posit that a crisis not only disrupts the social order of an organization but may cause damage to an organizations reputation and legitimacy. These authors further indicate that reputation is regarded as a valuable intangible asset to the organization and therefore a lack of a crisis response strategy may affect the organizations internal and external stakeholders as well as damage its long-term response strategies. Tench and Yeoman (2006) state that, the key to crisis management is "preparedness", therefore it is imperative that organizations devise a crisis plan which will assist them in successfully managing crisis situations. The development of communication strategies and processes to influence the course of conflicts could benefit the higher education institutions and their many constituents. For example recurring strikes continually disrupt the academic program during each semester. MacGregor, (2009) reports that Universities open for the academic year in January or February, often to the prospect of students protesting about academic exclusions, registration fees, financial difficulties or other problems such as lack of accommodation. Universities should rather be proactive and conduct activities and thought processes that can prevent a conflict from arising or from getting out of hand.

Strategic phase: In this phase, an issue that has become an emerging conflict is identified as needing concentrated action by the public relations practitioner. Two strategies take place in this phase are risk communication and the implementation of the organizations crisis plan.

Risk Communication: Risk communication refers to any verbal or written exchange that attempts to communicate information that puts the organization in a favourable position. Zhuldz et al. (2013) explains that, during risk communication an organization has to be able to answer when to communicate, what to communicate, with whom to communicate, by whom to communicate, and how to communicate. Based on this criterion Zhuldz et al. (2013) further elaborates:

- Who is responsible to communicate - The public relations department would be responsible to manage a particular risk and effectively communicate with the internal and external publics

- When to communicate - Risk communication needs both proactive and ongoing communication.

- What to communicate - By looking at the risk at hand, a risk communication program can be developed. It is essential to consider your audiences needs, interests and knowledge level when designing the content of the message.

- With whom to communicate - The general audiences for risk communication include the general public, the media, and interested public as well as key stakeholders.

- How to communicate - The content that is to be communicated may be different however the technique of risk communication is very much the same as other communication techniques. Some forms of communication are, brochures and leaflets, television and internet presentations, public meetings, face-to-face meetings, press releases and press conferences.

Poor risk communication often produces intense crisis, whereas good risk communication can direct and diminish the impact of a crisis event.

Crisis Communication Plan: The successful existence of organizations depends on how well it has prepared for a crisis therefore it is vital that management set up a crisis communication plan. Borodzicz (2005) explains that by successfully executing such a plan it can be regarded as an acid test of an organizations commitment to building, sustaining and reinforcing the community of trust. The University of Toronto (2009) has maintained that when developing the crisis plan, key objectives should include To remove harmful/dangerous threats, to minimize the disruption to teaching and research as well as the physical and financial damage, to ensure prompt, open and honest communication with the internal and external stakeholders, to restore normal operations rapidly and effectively and prevent a recurrence of the incident and improve future responses. By developing such objectives, a base can be formulated for the development of a completed crisis management plan. In conjunction with these objectives the following are key considerations which should be reflected upon: 
- Does our organization have a policy on crisis preparedness or response strategies?

- What is a crisis and what are the different types of crisis that could affect our organization?

- Who are the possible members to form part of the crisis team what roles and responsibilities should be delegated to them?

- What key resources do we possess, and how will we disseminate information about the crisis to key stakeholders?

- What methods are used for post-evaluation of a crisis?

Crises can happen anywhere, at any time and often occur when they are least expected. When a crisis does occur, events usually unfold rapidly, leaving little time for planning, therefore advance preparation is essential.

All Africa (2013) reports that Walter Sisulu University has been plagued with various challenges since its formation in 2005. In November 2011, the Minister of Higher Education and Training, Blade Nzimande placed Walter Sisulu University under administration in an effort to fix the financial woes and governance issues the institution was facing. Over the years there have been protests from staff and students alike for issues pertaining to salary increases and exam results. The above implies that this is an emerging issue which requires concentrated action. Higher education institutions could use the public relations team to:

- Monitor for potential threats/conflicts

- Assess threats/conflicts

- Develop a position the institution on the identified threats

- Develop a communications plan to address potential threats

- Begin communication efforts based on the identified position by management and its public relations department.

Reactive phase: Lubbe and Puth (2000) posit that once the issue of imminent conflict reaches a critical level of impact on the organization, the public relations practitioner must react to events in the external communication environment as they unfold. Only through participation and co-operation can top management successfully implement the crisis plan. It is also important for the organization to stay focused and motivated so that they may survive the crisis. Kanel (2008) explains that this is the phase in which tough decisions have to be made and made fast and therefore it is essential that an organization have a dedicated group of individuals to manage the crisis. These individuals make up the crisis management team of an organization.

Crisis Management Team: The Cowley College (2012) has deduced that a crisis management team is created by an organization and includes a range of individuals to whom roles and responsibilities are delegated to. During a crisis, it is this team which responds and reacts appropriately to resolve the issue at hand. The University of Toronto (2012) has identified possible members to form this team as well as their responsibilities. This may include a team leader, who will select additional specialist members to join this group and call meetings as required, and brief all members of the crisis team. They are also responsible to declare the crisis being over. Logistics and support personnel who will ensure that the crisis plan is reviewed annually and all members have a copy of this plan, implement training sessions and gathering of accurate information. Communication personnel, who will prepare communication procedures, identify notification systems and prepare standard media messages to communicate with the internal and external stakeholders. Finance personnel who will ensure that adequate insurance coverage is maintained and collect necessary information for the preparation of an insurance claim. Legal personnel who will identify legal resources that might be of assistance to the organization during a crisis and identify legal requirements and constraints on action related to potential crisis. They should also be able to advise on legal aspects that need to be considered in resolving the crisis and a secretary to provide the necessary administrative support.

Crisis Communication: Crisis situations are often regarded as newsworthy events and have the ability to generate media interest. The media will expect press statements and explanations regarding the cause and effects of the crisis. Organizations that do not provide information to its stakeholders during a crisis force its employees, the community and the media to turn to other, less credible sources for information. The Berkley University of California (2012) highlights that it is imperative to communicate to key stakeholders and communication methods need to also be identified. Other communication instruments that may be used are, "WarnMe" text messages, voicemail messages, a crisis webpage and bulk e-mails. Schultz et al. (2011), purport that the rise of social media has played an increasing role in the social 
construction and deconstruction of a crises. Social feeds and networks are often regarded as efficient communication tools and they are more dialogical interactive, and fast. Liu, Austin and Jin (2011) outline that social networks and blogs account for one in every four and half minutes spent online worldwide and during a crisis, publics will spend even more time online. In keeping with this, organizations, especially universities should consider incorporating social media networks into their communication systems. Donyale et al. (2013) assert that, during a crisis, communication to key stakeholders is vital. The media is used as a tool to communicate to these key stakeholders. With the rise of social media, the public considers the internet to be the most reliable source for news. This is seen as an ideal method for generating timely communication, unique information and interactive conversations. By organizations not communicating frequently, key stakeholders may believe rumours which will circulate during the crisis, therefore constant communication will be perceived as a form of reassurance by stakeholders. The University of Cape Town (2008) reported that during crisis situations communication needs to be expanded as it plays a vital role in reducing anxiety, managing expectations, demonstrating concern, and building trust during crisis situations. The above implies that universities are recognizing that communication is pivotal during crisis situations. Therefore, the issue of communication at higher education institutions during crisis needs to be further probed.

Recovery phase: Fernandez and Merzer (2005) postulate that after the crisis has ended, the crisis management team is responsible for, declaring an end to the crisis; Following up with stakeholders; keep the media informed of any updates in the situation; Perform an act of goodwill. Do this during or immediately after the crisis, when appropriate and possible; and conduct a post-incidental analysis. This is an exercise for all members of the crisis communication team/management to reflect on the events as they transpired and to communicate ideas for policy and procedure improvement. In the aftermath of a crisis, the organization should implement strategies to repair its reputation. Reputation management includes the systematic research to earn the state of the organizations reputation. One should also take the necessary steps to improve it. As conflicts occur the organizations responds with actions of communication. Poorly managed issues and callous responses to a crisis can further damage an organization reputation. This highlights that all crises are intrinsically linked with reputation management. When this damage is extreme image restoration strategies can be extremely helpful. The above shows that once a crisis is over, it is the responsibility of the crisis communication team, together with the Management of the university to reflect and analyze on the crisis and the steps taken to resolve the crisis. Bond (2008) reinforces that an academic institutions sterling reputation can be damaged by the persistent negative publicity received during a crisis, therefore in the aftermath of a crisis, the organization should implement strategies to repair its reputation. The literature has been used as a framework to compile the research instrument for this study in order to further probe the extent to which higher education institutions engage in crisis communication management. The next section discusses the research methodology that was employed for this study.

\section{Methodology}

Research Approach: A qualitative descriptive methodology was employed for this study. Houser (2008) describes descriptive research as a type of study that tries to find out what, why, who or where. This study aimed to describe the gaps that exist in the practices of crisis communication at higher education institutions.

Target population: The target population comprised of all public higher education institutions in KwaZulu-Natal. All communication and media officers within the Division of Corporate Affairs at all public higher education institutions in KwaZulu-Natal were contacted to participate in the study.

Measuring Instrument: Themes emanating from the literature review were used to develop an interview schedule which comprised both open and closed ended questions. Data was collected via faceto-face interviews with the communication and media officers.

Data analysis: Data was analyzed using thematic analysis. Braun and Clark (2006) describe thematic analysis as a method for identifying, analyzing and reporting on patterns (themes) within the data that is collected. Braun and Clark (2006) further maintain that a theme captures something important about the data in relation to the research question and represents some level of patterned response within the data set. To identify the gaps that existed in the practice of crisis communication, common themes emanating from the literature review were used to interpret and analyze the findings from the interviews. 


\section{Results and Discussion}

The findings are reported and contextualised against the themes identified from the literature review which include the proactive, strategic, reactive and recovery phase.

Proactive Phase - Strategic Conflict management: Findings have revealed that majority (75\%) of the institution's strategic plan does address the management of conflict. The findings support Zhuldz et al. (2013) assertions that an organizations capability to solve conflicting situations is considered a priority as successfully managing conflicts can reduce future costs associated with those issues. It also elevates the role of a public relations practitioner of reacting to events to a more proactive, responsive role of anticipating and reducing emerging conflict.

Proactive Phase - Issues Management: Majority (75\%) of the respondents have indicated that issues management is conducted using environmental scanning. The results concur with statements made by Barton (2008) who mentions that environmental scanning refers to the constant reading, listening and watching of current affairs, with an eye to the organizations interests. These findings are also an indication that most institutions are constantly monitoring the environment for changes that could affect them and plan ways in which these issues are addressed. By constantly monitoring the environment issues that have the potential to turn into a crisis can be identified and action can be taken to resolve such issues. The data is consistent with statements by Wilcox and Cameron (2009), who assert that proactive and systematic planning can be effectively used to predict problems, anticipate threats, minimizes surprises, resolve issues and prevent crises.

Strategic Phase - Crisis plan: 75\% of the respondents have indicated that their institutions have a crisis plan. When further probed regarding the components of this plan, varied responses were received. One of respondents explained that the plan should include how the university should carry out itself during a crisis as well as techniques to handle the media; another respondent highlights that risk management, insurance management and student management forms part of the crisis plan. Another respondent indicated that there was no crisis plan and the last respondent indicated that it is an internal document and contents cannot be disclosed. Literature has revealed that, the successful existence of an organization depends on how well it has prepared for a crisis; therefore it is vital for all organist ions to develop a crisis plan. Nowadays, crises have become an inescapable reality which needs to be included into all planning and decision making strategies. The responses received surmise Borodzicz (2005) statements which reveal that, by having a crisis plan as an organization will have taken the first step in anticipating, containing and responding to the most likely threats facing it. With two of the respondents being unaware of the components of the crisis plan, it is an indication that these universities are inadequately prepared to successfully manage a crisis. Respondents have also mentioned that, a crisis plan should include media and communication techniques as well as risk communication. Borodzicz (2005) elaborates that the crisis plan should outline roles, responsibilities and protocols which will be used to guide the organization in sharing information with the internal and external stakeholders by outlining: Who is responsible to communicate? When to communicate? What to communicate? With whom to communicate? How to communicate? In comparison to Borodzicz statements and those of the respondents indicate that majority of the universities have included key issues in their crisis communication plan.

Reactive Phase - Crisis Communication Team: All respondents indicated that their institutions have a crisis team and common representatives of a crisis team include Top Management, Council, Security, Corporate Affairs, Health and Safety, Legal Department, Student Counseling and Student Affairs. The crisis communication team plays an integral role within the crisis plan. This team will encompass member from management and key roles and responsibilities will be assigned to each member. The findings infer with that of The Cowley College (2012) who have indicated that during a crisis, it is this team which responds and reacts appropriately to resolve the issue at hand. The findings are also supported by the University of Toronto (2012) who has confirmed that key members of the crisis team include a team leader, communication representative, logistics and support representative, finance representative, legal representative and an administrative assistant. The findings together with the literature presented can assist universities and other organizations in selecting members to their crisis management team and it further suggests the type of responsibilities which can be allocated to these individuals. In keeping with universities, possible members to be included are members of Council, Executive management, Vice Chancellor, Director: Division of Corporate Affairs, Finance and security. It is these members who are entrusted with successfully managing the Universities operation and therefore will play a vital role 
during a crisis. Whilst the formation of a crisis team is vital to an institution, a key question that still remains is the extent to which members of the crisis team are assigned roles and responsibilities and if they are trained. Therefore it is recommended that emphasis be placed on selecting appropriate members for this team and ensuring that the members are trained to perform their allocated tasks effectively.

Reactive Phase - Role of Communication during a crisis: All respondents have agreed that communication is integral during crisis situations. Respondents have further highlighted that the staff intranet is used predominantly $(100 \%)$ as an internal method of communication for employees. Flyers were the other form of communication to staff (20\%). External communication consisted predominantly $(100 \%)$ newspapers and radio. Television as a tool of communication was minimally (20\%).considered as a tool for external communication. During a crisis situation, clear communication structures need to be in place to enable efficient coordination of communication strategies. Should gaps appear within the communication process, it may hinder the decision making and create a negative impact. The findings concur with the Berkley University of California (2012) who assert that, communication during a crisis is essential and therefore key stakeholders and methods of communicating to these stakeholders need to be identified. Universities should be proactive and implement innovative communication modes and also communication instruments which are familiar with e.g. "WarnMe" text messages, voicemail messages, a crisis webpage and bulk e-mails. In addition to these instruments, Liu, Austin and Jin (2011) believe that social media technologies are tools which are more dialogical, interactive and fast and should therefore be incorporated into communication strategies. Common modes of social media technologies that can be used include, Facebook, Blogs and Twitter feeds.

Recovery Phase - Post crisis evaluation: Most respondents (75\%) indicated that they conducted evaluations after the crisis and in most cases action plans were put in place. One of the respondents indicated that "We do post-mortems after events and even after strikes etc so we can see what we can improve upon. After the crisis one needs to evaluate the effectiveness of this crisis plan and how people responded to it. Correct the problems that arose so that they don't happen again. One of the best ways of performing an evaluation is to look at the various media coverage. The crisis communication team should convene after the crisis ends to evaluate every action taken and the crisis communication plan as well. Thereafter, the crisis communication plan is updated. It is important to learn from successes and mistakes made. The findings are consistent with Fernandez and Merzer (2005) who maintain that post crisis evaluation assists an organization in evaluative its effectiveness and abilities to manage a crisis. Additionally, if a crisis is effectively managed, it can be seen as an opportunity. Therefore, messages that management sends out to the media should be positive and media reports should be used as tool in conducting post crisis evaluation.

\section{Conclusion and Recommendations}

Based on the literature review and the empirical study this study draws the following conclusions and recommendations:

- Although most higher education institutions incorporate conflict management and crisis communication in their strategic plans a few of them still do not consider this a priority. It is therefore recommended that this aspect should be a pre-requisite of every higher education institution.

- Higher Education Institutions should develop a Risk Policy. This policy should include the role of public relations and communication.

- Issue management should be conducted in a more strategic manner so that risks are identified and planned for. It is recommended that issue management is considered a priority at higher education institutions and be incorporated into the institutions Risk Policy.

- It is positive that most crisis teams are made up of key stakeholders. Senior management should continue to consider this as an institutional priority to alleviate financial loss. These members should be adequately trained as well.

- Large staff and student numbers; multi campuses; legal and health issues have created additional challenges for communication during crisis. It is recommended that a plan of action is sought to address these issues.

- More instantaneous communication and the incorporation of social media should be considered a priority as this will alleviate confusion and will ensure clearer communication. 


\section{References}

allAfrica (2013). South Africa: Strike At Walter Sisulu University Enters Its Second Week - Urgent Action Needed (online). Available http://allafrica.com/stories/201308011144.html (Accessed 10 January 2014).

Barton, L. (2008). Crisis leadership now: A real-world guide to preparing for threats, disasters, sabotage and scandal. New York: McGraw Hill.

Bond, P. (2008). UKZN crisis: sink or spin (online). Available: http://lists.fahamu.org/pipermail/debatelist/2008-December/018844.html (Accessed on 10 January 2014)

Borodzicz, E. P. (2005). Risk, Crisis and Security management. England: John Wiley and Son Ltd.

Braun, V. \& Clarke, V. (2006). Using thematic analysis in psychology. Qualitative research in psychology, Available at www.qualresearchpsych.com (Accessed on 16 March 2009).

Center, A., Jackson, P., Smith, S. \& Stansberry, F. R. (2008). Public relations practices: Managerial case studies and problems. (7th Ed.). United States of America: Prentice Hall.

Donyale, R., Griffin, P., Shuhui, S. C. \& Parekh, V. (2013). The Quest for Transparency and Accountability: Communicating Responsibly to Stakeholders in Crises. Asian Social Science, 9(9), 31-44.

Fernandez, L. \& Merzer, M. (2005). Jane's crisis communication handbook. Coulsdon: Jane's information group.

Higher Education South Africa. (2008). Strategic Plan. Available at www.hesa.org/hesa/strategicplan.com (Accessed on 28 October 2013).

Houser, J. (2008). Nursing Research: Reading, using and creating research, Jones \& Bartlett Publishers, Denver.

Kanel, K. (2008). A guide to crisis intervention. Belmont: Thomson Brooks Publishing.

Liu, B. F., Austin, L. \& Jin, Y. (2011). How publics respond to crisis communication strategies: The interplay of information form and source. Public Relations Review, 37, 345-353.

Lubbe, B. A. \& Puth, G. (2000). Public Relations in South Africa: A management reader. Isando: Heinemann publishers.

MacGregor, K. (2009). South Africa: Universities Hit by Protests, Strikes. University World News, 8, 22.

May, T. (2004). An evaluation of goal clarity, trust in management and perceptions of organizational readiness for change at Durban Institute of Technology (online). Available at http://www.actacommercii.co.za/index.php/viewFile/23/23. (Accessed on 14 Mar 2009).

Ministry of Education. (2001). National Plan for Higher Education. Available at www.education.gov.za/document/policies/nationalplanhighereducation.com (Accessed 14 March 2009).

Pityana, N. B. (2004). Higher education in South Africa: Future Perspectives. Available at www.unisa.ac.za/contents/about/principle/docs/AltronAwardsspeech, (Accessed on 17 March 2009).

Plowman, K. D. (2005). Conflict strategic management and public relations. Public Relations Review, 31, 131-138.

Schultz, F., Utz, S. \& Goritz, A. (2011). Is the medium the message? Perceptions of and reactions to crisis communication via twitter, blogs and traditional media. Public Relations Review, 37, 20-27.

Skinner, J. C. \& Mersham, G. (2002). Disaster management: A guide to issues and crisis communication. Cape Town: Oxford University Press.

Tench, R. \& Yeoman, L. (2006). Enhancing Public Relations. Harlow: Prentice Hall.

The Berkeley University of California. (2012). Crisis Communication Plan (online). Available http://oep.berkeley.edu/campus_disaster_response/documents/2012CampusCrisisCommunicat ionPlan.pdf (Accessed 28 October 2013).

The Cowley College. (2012). Crisis Management Plan (online). Available http://www.cowley.edu/security/crisismanagement.pdf (Accessed 1 November 2013)

The University of Toronto. (2009). Emergency preparedness and crisis management plan (online). Available:http://www.preparedness.utoronto.ca/Assets/Preparedness+Digital+Assets/Crisis+Pl anning/Emergency+Preparedness+and+Crisis+Management+Plan.pdf (Accessed 1 Nov 2013).

University of Cape Town. (2008). UCT's first response to the crisis (online). Available http://www.uct.ac.za/usr/news/2008/UCT_Crisis_response.pdf (Accessed 10 Jan 2014).

Wilcox, D. L. \& Cameron, G. T. (2009). Public relations: Strategies and tactics. Ninth edition. Boston: Pearson Education.

Zhuldz, I., Onaichan, K., Surugiu, F. \& Mina, S. (2013). Communication's management in crisis and conflict situations. Constanta Maritime University Annals (online), 19: 287 -291. Available http://ideas.repec.org/a/cmc/annals/v19y2013i1p287-292.html (Accessed 28 October 2013). 